\title{
HUBUNGAN PEMBERIAN ASI EKSKLUSIF, PENYAKIT INFEKSI DAN TINGKAT PENGETAHUAN IBU TENTANG GIZI DENGAN KEJADIAN STUNTING PADA BALITA USIA 12-36 BULAN DI WILAYAH KERJA PUSKESMAS KECAMATAN BAITURRAHMAN BANDA ACEH
}

\author{
The Relationship Of Exclusive Assessment, Infection Disease And The Level Of \\ Knowledge Mother About Nutrition With Stunting Events In Age 12-36 \\ Months In The Working Area Of Puskesmas District, Baiturrahman, Banda \\ Aceh \\ ${ }^{1}$ Ruri Widyasari, ${ }^{2}$ Chalida Aulia Putri \\ 1,2Fakultas Ilmu Kesehatan, Universitas Ubudiyah Indonesia, Banda Aceh
}

Email: ruri@uui.ac.id

\begin{abstract}
ABSTRAK
Dinas kesehatan Aceh menemukan prevalensi kejadian stunting tahun 2016 yaitu sebesar 26,4\% dan di kabupaten Aceh Tengah dengan prevalensi 27,0\% yang termasuk dalam kategori medium yang menjadi permasalahan pada balita. Penelitian ini bertujuan untuk mengetahui hubungan pemberian ASI eksklusif, penyakit infeksi dan tingkat pengetahuan ibu tentang gizi dengan kejadian stunting pada balita usia 12-36 bulan di wilayah kerja Puskesmas Kecamatan Bintang Kabupaten Aceh Tengah. Jenis penelitian yang digunakan adalah penelitian kuantitatif dengan disain case control. Sampel dalam penelitian ini berjumlah 60 balita usia 12-36 bulan yang didapat dengan metode total sampling perbandingan 1:1 (kasus:kontrol). Penelitian ini dilakukan bulan April 2018. Cara pengumpulan data dilakukan melalui pengukuran tinggi badan dan wawancara koesioner, analisa data dilakukan dengan uji chi-square. Dari hasil penelitian menunjukan bahwa proporsi responden yang stunting sebesar $50 \%$ dan yang memiliki status gizi normal sebesar $50 \%$. Kemudian sebanyak $26,7 \%$ balita tidak diberi ASI eksklusif, $28,4 \%$ balita mengalami penyakit infeksi pada 2 minggu terakhir dan 36,7\% ibu memiliki tingkat pengetahuan tentang gizi dengan kategori kurang. Analisis uji statistik menunjukan adanya, hubungan bermakna antara pemberian ASI eksklusif, penyakit infeksi dan tingkat pengetahuan ibu tentang gizi dengan kejadian stunting pada balita. Penelitian ini menyarankan agar peran aktif petugas kesehatan dan masyarakat mengetahui lebih dini kejadian stunting pada balita untuk lebih cepat diberi penanganan lebih lanjut.
\end{abstract}

Kata Kunci : Stunting, balita, ASI eksklusif, penyakit infeksi, pengetahuan ibu.

\begin{abstract}
The Aceh health office found the prevalence of stunting in 2016 was $26.4 \%$ and in Central Aceh district with a prevalence of $27.0 \%$ which was included in the medium category which was a problem for toddlers. This study aims to determine the relationship of exclusive breastfeeding, infectious diseases and the level of maternal knowledge about nutrition with the incidence of stunting in infants aged 12-36 months in the work area of the District Health Center, Bintang Aceh Tengah District. This type of research is a quantitative study with case control design. The sample in this study amounted to 60 toddlers aged 12-36 months obtained with a total sampling method of 1: 1 comparison (case: control). This research was conducted in April 2018. The method of data collection was carried out through height measurements and questionnaire interviews, data analysis was performed with the chi-square test. The results showed that the proportion of respondents who stunted by $50 \%$ and who had normal nutritional status by $50 \%$. Then as many as $26.7 \%$ of children under five were not exclusively breastfed, $28.4 \%$ of infants had infectious diseases in the last 2 weeks and $36.7 \%$ of mothers had a level
\end{abstract}


of knowledge about nutrition in the poor category. Statistical analysis showed that there was a significant relationship between exclusive breastfeeding, infectious diseases and the level of maternal knowledge about nutrition and the incidence of stunting in infants. This study suggests that the active role of health workers and the public in knowing early on the incidence of stunting in infants to be given faster treatment.

Keywords: Stunting, toddlers, exclusive breastfeeding, infectious diseases, mother's knowledge.

\section{PENDAHULUAN}

Salah satu indikator kesehatan yang dinilai keberhasilan pencapaiannya dalam MDGs adalah status gizi anak balita. Masa anak balita merupakan kelompok yang rentan mengalami kurang gizi salah satunya adalah stunting. Stunting (pendek) merupakan ganguan pertumbuhan linier yang disebabkan adanya malnutrisi asupan zat gizi kronis atau penyakit infeksi kronis maupun berulang yang ditunjukkan dengan nilai z-score tinggi badan menurut umur (TB/U) kurang dari -2 SD (Nasikhah, 2012).

Menurut (Riskesdas, 2016) di Provinsi Aceh prevalensi stunting pada tahun 2015 sebanyak 31,6\% (sangat pendek yaitu 11,6\% dan pendek 20,0\%) dan pada tahun 2016 mengalami penurunan yaitu 26,4\% (sangat pendek yaitu 7,6 \% dan pendek 18,8\%).

Pemberian ASI juga berhubungan dengan pertumbuhan panjang badan anak. Durasi menyusui positif berhubungan dengan pertumbuhan panjang, semakin lama anak-anak disusui, semakin cepat mereka tumbuh baik pada kedua dan tahun ketiga kehidupan (Adair dan Guilkey, 1997). dan Menurut (Onayade, et al., 2004) ASI eksklusif selama 6 bulan mendukung pertumbuhan bayi dalam 6 bulan pertama kehidupannya. Bayi yang diberi ASI eksklusif berat badan dan panjang badannya bertambah dengan cukup dan berisiko lebih kecil menderita penyakit demam, diare dan ISPA dibandingkan yang diberikan MPASI sebelum usia 6 bulan.

Masa balita keadaan gizi yang baik dan sehat merupakan fondasi penting bagi kesehatannya di masa depan. Kekurangan gizi yang terjadi pada masa tersebut dapat mengakibatkan terganggunya pertumbuhan dan perkembangan. Proses tumbuh kembang yang pesat terutama terjadi pada usia 1-3 tahun (Sutomo dan Aggraini, 2010).

Balita stunting pada massa anak-anak merupakan konsekuensi dari beberapa faktor yang sering dikaitkan dengan kemiskinan termasuk gizi, kesehatan, sanitasi dan lingkungan. Ada lima faktor utama penyebab stunting yaitu kemiskinan, sosial dan budaya, peningkatan paparan terhadap penyakit infeksi, kerawanan pangan dan akses masyarakat terhadap pelayanan kesehatan (Kemenkes RI, 2013). 


\section{METODE PENELITIAN}

Jenis penelitian yang digunakan adalah penelitian kuantitatif dengan disain case control yaitu mengukur variabel dependen dan variabel independen secara bersamaan pada saat penelitian, yang bertujuan untuk mengetahui adakah perbedaan kejadian stunting dengan normal pada balita yang diberi ASI eksklusif, mengalami penyakit infeksi dan tingkat pengetahuan ibu tentang gizi.

Dari populasi penelitian yang dijadikan sampel dalam penelitian ini adalah balita yang memenuhi kriteria inklusi sebagai berikut : Kriteria inklusi kasus yang diajukan adalah :

1. Balita yang tinggal di Wilayah Kecamatan Bintang Kabupaten Aceh tengah

2. Balita Berusia 12-36 bulan

3. Balita dengan status gizi stunting

4. Ibu balita bersedia menjadi responden dalam penelitian ini.

5. Ibu balita yang mendampingi balita dalam penelitian ini.

Intrumen yang digunakan adalah microtoice, timbangan berat badan, dan kuesioner. microtoice digunakan untuk mengukur tinggi badan (TB) balita dengan ketelitian $0,1 \mathrm{~cm}$. Berat badan diperoleh dengan menggunakan timbangan berat badan dengan ketelitian $0,1 \mathrm{~kg}$. Kuesioner digunakan sebagai pedoman wawancara untuk mengetahui identitas ibu responden, identitas balita, pemberian ASI eksklusif pada balita, penyakit infeksi yang diderita oleh balita dan pengetahuan ibu tentang gizi.

\section{HASIL DAN PEMBAHASAN}

Hubungan antara Pemberian ASI Eksklusif dengan Kejadian Stunting di Wilayah Kerja Puskesmas Kecamatan Bintang.

Tabel 1. Hubungan antara Pemberian ASI Eksklusif dengan Kejadian Stunting pada Balita Usia 12-36 Bulan di Wilayah Kerja Puskesmas Kecamatan Bintang

\begin{tabular}{|c|c|c|c|c|c|c|c|c|}
\hline \multirow{3}{*}{$\begin{array}{c}\text { Pemberian } \\
\text { ASI } \\
\text { Eksklusif }\end{array}$} & \multicolumn{6}{|c|}{ Status Gizi TB/U } & \multirow{3}{*}{$\begin{array}{c}\text { OR } \\
(95 \% \\
\text { CI })\end{array}$} & \multirow{3}{*}{$\begin{array}{c}\mathbf{P} \\
\text { Value }\end{array}$} \\
\hline & \multicolumn{2}{|c|}{ Stunting } & \multicolumn{2}{|c|}{ Normal } & \multicolumn{2}{|c|}{ Total } & & \\
\hline & $\mathrm{n}$ & $\%$ & $\mathrm{n}$ & $\%$ & $\mathrm{n}$ & $\%$ & & \\
\hline $\begin{array}{c}\text { ASI } \\
\text { Eksklusif }\end{array}$ & 18 & 40,1 & 26 & 59,9 & 44 & 100 & 4,333 & 0,041 \\
\hline $\begin{array}{l}\text { Tidak ASI } \\
\text { Eksklusif }\end{array}$ & 12 & 75 & 4 & 25 & 16 & 100 & $\begin{array}{l}(1,203- \\
15,605)\end{array}$ & \\
\hline
\end{tabular}


$50 \quad 60$

100 
Journal of Healthcare Technology and Medicine Vol. 4 No. 2 Oktober 2018

Universitas Ubudiyah Indonesia

e-ISSN : 2615-109X

Tabel 1 memperlihatkan hasil uji statistik diperoleh nilai $\mathrm{p}=0,041 \quad(\mathrm{p}<0,05)$ dapat disimpulkan bahwa terdapat hubungan yang bermakna antara pemberian ASI eksklusif dengan kejadian stunting pada balita di Wilayah Kerja Pukesmas Kecamatan Bintang. Selain itu diperoleh juga nilai OR (odds Ratio) 4,333 (95\% CI:1,203-15,605) hal tersebut menunjukan bahwa tidak memberikan ASI eksklusif memiliki peluang 4,333 kali balitanya mengalami stunting dibandingkan dengan balita yang diberikan ASI eksklusif di Wilayah Kerja Puskesmas

Kecamatan Bintang.

\section{Hubungan antara Penyakit Infeksi dengan Kejadian Stunting di Wilayah Kerja Puskesmas Kecamatan Bintang.}

Tabel 2. Hubungan antara Penyakit Infeksi dengan Kejadian Stunting pada Balita Usia 12-36 Bulan di Wilayah Kerja Puskesmas Kecamatan

\begin{tabular}{|c|c|c|c|c|c|c|c|c|}
\hline \multirow{4}{*}{$\begin{array}{c}\text { Katagori } \\
\text { Penyakit } \\
\text { Infeksi }\end{array}$} & \multicolumn{8}{|c|}{ Bintang } \\
\hline & \multicolumn{4}{|c|}{ Status Gizi TB/U } & & & \multirow{3}{*}{$\begin{array}{c}\text { OR } \\
(95 \% \\
\text { CI })\end{array}$} & \multirow{3}{*}{$\begin{array}{c}\mathbf{P} \\
\text { Value }\end{array}$} \\
\hline & \multicolumn{2}{|c|}{ Stunting } & \multicolumn{2}{|c|}{ Normal } & \multicolumn{2}{|c|}{ Total } & & \\
\hline & $\mathrm{n}$ & $\%$ & $\mathrm{n}$ & $\%$ & $\mathrm{n}$ & $\%$ & & \\
\hline Sakit & 14 & 82,3 & 3 & 17,7 & 17 & 100 & 7,875 & 0,004 \\
\hline $\begin{array}{l}\text { Tidak } \\
\text { Sakit }\end{array}$ & 16 & 37,2 & 27 & 62.8 & 43 & 100 & $\begin{array}{l}(1,958 \\
31,675)\end{array}$ & \\
\hline Jumah & 30 & 50 & 30 & 50 & 60 & 100 & & \\
\hline
\end{tabular}

Berdasarkan hasil bivariat yang disajikan pada tabel 2 meperlihatkan hasil uji statistic diperoleh nilai $\mathrm{p}=0,004(\mathrm{p}<0,05)$ dengan demikian dapat disimpulkan bahwa terdapat hubungan yang bermakna antara penyakit infeksi dengan stunting pada balita di Wilayah Kerja Puskesmas Kecamatan Bintang.

Berdasarkan uji statistik juga diperoleh OR (odds rasio) 7,875 (95\% CI:1,958-31,675) hal tersebut menandakan bahwa balita mengalami penyakit infeksi mempunyai peluang 7,875 kali menjadi stunting dibandingkan dengan balita yang tidak mengalami penyakit infeksi pada balita di Wilayah kerja Puskesmas Kecamatan Bintang. 
Journal of Healthcare Technology and Medicine Vol. 4 No. 2 Oktober 2018

Universitas Ubudiyah Indonesia

e-ISSN : 2615-109X

\section{Hubungan antara Tingkat Pengetahuan Ibu tentang Gizi dengan Kejadian Stunting di Wilayah Kerja Puskesmas Kecamatan Bintang.}

Tabel 3 Hubungan antara Tingkat Pengetahuan Ibu tentang Gizi dengan

Kejadian Stunting di Wilayah Kerja Puskesmas Kecamatan Bintang

\begin{tabular}{|c|c|c|c|c|c|c|c|c|}
\hline \multirow{3}{*}{$\begin{array}{c}\text { Kategori } \\
\text { Tingat } \\
\text { Pengetahuan } \\
\text { Ibu }\end{array}$} & \multicolumn{6}{|c|}{ Status Gizi TB/U } & \multirow{3}{*}{$\begin{array}{c}\text { OR } \\
(95 \% \\
\text { CI })\end{array}$} & \multirow{3}{*}{$\begin{array}{c}\mathbf{P} \\
\text { Value }\end{array}$} \\
\hline & \multicolumn{2}{|c|}{ Stunting } & \multicolumn{2}{|c|}{ Normal } & \multicolumn{2}{|c|}{ Total } & & \\
\hline & $\mathrm{n}$ & $\%$ & $\mathrm{n}$ & $\%$ & $\mathrm{n}$ & $\%$ & & \\
\hline Cukup & 14 & 36,8 & 24 & 63,2 & 38 & 100 & 4,571 & 0,016 \\
\hline Kurang & 16 & 72,7 & 6 & 27,3 & 22 & 100 & $(1,452-$ & \\
\hline Jumah & 30 & 50 & 30 & 50 & 60 & 100 & $14,389)$ & \\
\hline
\end{tabular}

Tabel 3 memperlihatkan hasil uji statistik menghasilkan nilai $\mathrm{p}=0,016(\mathrm{p}<0,05)$ hal tersebut menunjukan bahwa ada hubungan yang bermakna antara tingkat pengetahuan dengan kejadian stunting pada balita di wilayah selain itu diperoleh juga nilai OR (odds rasio) sebesar 4,571 (95\% CI: 1,452-14,389) artinya ibu dengan tingkat pengetahuan kurang beresiko 4,571 kali balitanya mengalami stunting dibandingkan dengan ibu tingkat pengetahuan cukup di Wilayah kerja Puskesmas Kecamatan Bintang.

ASI eksklusif adalah memberikan hanya ASI saja bagi bayi sejak lahir sampai berusia 6 bulan. Namun ada pengecualian, bayi diperbolehkan mengkonsumsi obat-obatan, vitamin, dan mineral tetes atas saran dokter. Salama 6 bulan pertama pemberian ASI eksklusif, bayi yang tidak diberikan makanan dan minuman lain (Kemenkes 2010).

Hasil penelitian menunjukan bahwa $(26,7 \%)$ balita dari sampel tidak diberikan ASI eksklusif dan (73,3\%) diberikan ASI eksklusif. Berdasarkan hasil bivariat pada tabel 4.5 memperlihatkan proporsi balita yang tidak mendapatkan ASI eksklusif memiliki status gizi stunting lebih banyak yaitu sebesar 75\% dibandingkan dengan balita yang diberi ASI eksklusif. Di peroleh nilai $\mathrm{p}<0,05$ dari hasil uji statistik, dengan demikian adanya hubungan yang bermakna antara pemberian ASI eksklusif dengan kejadian stunting pada balita usia 12-36 bulan di Wilayah Kerja Puskesmas Kecamatan Bintang.

Hasil penelitian ini menunjukkan sejumlah 16 responden $(26,7 \%)$ tidak memberikan ASI Eksklusif, hal ini dapat terjadi karena kurangnya pengetahuan ibu tentang ASI Eksklusif yang dapat dikarenakan pendidikan ibu yang rendah. Hasil penelitian menunjukkan mayoritas ibu yang berpendidikan SMA yaitu 24 ibu dimana 14 ibu yang berpendidikan SMA tidak 
Journal of Healthcare Technology and Medicine Vol. 4 No. 2 Oktober 2018

Universitas Ubudiyah Indonesia

e-ISSN : 2615-109X

memberikan ASI Eksklusif hal ini dapat dikarenakan ibu memiliki pengetahuan yang kurang tentang ASI Eksklusif dan ketika di wawancara sebagian besar ibu mengatakan ASI tidak keluar juga balitanya tidak cukup nutrisi dengan dikasih ASI saja. Hasil ini juga didukung penelitian Arifin (2012) yang meneliti faktor yang paling nyata menyebabkan kegagalan pemberian ASI eksklusif adalah faktor pengetahuan, didapat alasan mengapa ibu tidak memberi ASI eksklusif kepada bayinya adalah sebagian besar yaitu 51,35\% karena ibu tidak mengetahui tentang pemberian ASI eksklusif, 18,92\% karena ibu bekerja, 16,22\% karena ASI tidak keluar dan $13,51 \%$ ibu merasa bayinya tidak kenyang jika hanya diberi ASI.

Sejalan dengan teori dari Prasetyono (2009) bahwa salah satu manfaat ASI eksklusif adalah mendukung pertumbuhan bayi terutama tinggi badan karena kalsium ASI lebih efisien diserap dibanding susu pengganti ASI atau susu formula. Sehingga bayi yang diberikan ASI eksklusif cenderung memiliki tinggi badan yang lebih tinggi dan sesuai dengan kurva pertumbuhan dibanding dengan bayi yang diberikan susu formula. ASI mengandung kalsium yang lebih banyak dan dapat diserap tubuh dengan baik sehingga dapat memaksimalkan pertumbuhan terutama tinggi badan dan dapat terhindar dari resiko stunting.

Kurangnya pemberian ASI dan pemberian MP-ASI yang terlalu dini dapat meningkatkan risiko terjadinya stunting terutama pada awal kehidupan (Adair dan Guilkey, 1997). Besarnya pengaruh ASI eksklusif terhadap status gizi anak membuat

Hasil penelitian tingkat pengetahuan ibu tentang gizi lebih banyak dengan kategori kurang dikarenakan ketika wawancara ibu balita semua ibu mengatakan jarang mendapatkan penyuluhan tentang gizi, disebabkan karena wilayah kerja Puskesmas Kecamatan Bintang hanya memilki satu tenaga kerja gizi dari 26 posyandu dalam satu kecamatan sehingga kurangnya penyuluhan dan pelatihan yang didapatkan ibu balita tentang gizi membuat kurangnya pemahaman ibu dalam menerapkan dikehidupan sehari-hari.

Pengetahuan orang tua tentang gizi membantu memperbaiki status gizi pada anak untuk mencapai kematangan pertumbuhan. Pada anak dengan stunting mudah timbul masalah kesehatan baik fisik maupun psikis. Oleh karena itu, tidak semua anak dapat bertumbuh dan berkembang sesuai dengan usianya, ada anak yang mengalami hambatan dan kelainan (Gibney dkk, 2009). 
Journal of Healthcare Technology and Medicine Vol. 4 No. 2 Oktober 2018

Universitas Ubudiyah Indonesia

e-ISSN : 2615-109X

\section{KESIMPULAN}

1. Sebanyak $73,3 \%$ balita diberi ASI, dan $26,7 \%$ balita tidak diberi ASI eksklusif di Wilayah Kerja Puskesmas Kecamatan Bintang.

2. Sebanyak $28,4 \%$ balita mengalami sakit ISPA/Diare pada 2 minggu terakhir, dan 71,6\% tidak mengalami sakit ISPA/Diare pada 2 minggu terakhir di Wilayah Kerja Puskesmas Kecamatan Bintang.

3. Sebanyak $63,3 \%$ ibu memiliki tingkat pengetahuan tentang gizi dengan kategori “cukup" dan 36,7\% ibu memiliki tingkat pengetahuan tentang gizi dengan kategori "kurang" di Wilayah Kerja Puskesmas Kecamatan Bintang.

4. Ada hubungan yang bermakna antara pemberian ASI eksklusif dengan kejadian stunting pada balita usia 12-36 bulan di Wilayah Kerja Puskesmas Kecamatan Bintang.

\section{DAFTAR PUSTAKA}

Abuya, B.A., Ciera, J., \& Murage, E.K. 2012. Effect of Mother's Education on Child's Nutritional Status in The Slums of Nairobi : BMC Pediatrics, 12:80.

Aditianti. 2010. Faktor Determinan Stunting pada Anak Usia 24-59 Bulan di Indonesia. Jurnal Info pangan dan Gizi.

Gibney, J., Michael. 2009. Human Nutrition. Oxford : Wily-Black.

Hidayat, N. R. 2011. Faktor-faktor yang Berhubungan Dengan Kejadian Stunting pada Balita Usia 24-59 Bulan di Provinsi Nusa Tenggara Timur Tahun 2010 (Analisis Data Riskesdas 2010). Skripsi. Depok : FKM UI.

Hestuningtyas, Tiara R. 2013. Pengaruh Konseling Gizi terhadap Pengetahuan, Sikap, Praktik Ibu dalam Pemberian Makan Anak, dan Asupan Zat Gizi Anak Stunting Usia 1-2 Tahun di Kecamatan Semarang Timur. Skripsi : Program Studi Ilmu Gizi Fakultas Kedokteran Universitas Diponegoro Semarang.

Kurnia, S.W., Irviani A, I., Dwi, S.D. 2014. Hubungan asupan zat gizi dan penyakit infeksi dengan kejadian stunting anak usia 24-59 bulan di Posyandu Asoka II Kelurahan Barombong Kecamatan tamalate kota Makasar. Journal Fakultas Ilmu Kesehatan, Universitas Islam Negeri, Makassar.

Narsikhah, R. 2012. Faktor resiko kejadian stunting pada balita usia 24-36 bulan di kecamatan semarang timur. Journal UNDIP.

Nelson, W. E., Behrmen, K. 2002. Ilmu Kesehatan Anak Nelson edisi 15 vol 2. Jakarta : EGC

Supariasa, I.D.N. 2001. Penilaian Status Gizi. Jakarta: EGC

Taguri, A. E. 2008. Risk Factor for Stunting Among Under Fives in Libya. Public Health Nutrition: 12 (8). 1141-1149.

WHO. 2009. Diarrhoea. Diakses 16 Januari 2018. 